\title{
THE EFFECT OF QUINIDINE UPON SINLS TACHYCARIIA, INCLUDING THE PRODUCTION OF TRANSIENT BUNDLE BRANCH BLOCK
}

\author{
Paul S. Barker, M.D., Frankin D. Johrstox, M.D., and \\ Frank N. Wilson, M.D. \\ AÑ ArBor, Mich.
}

$\mathrm{T}$ HE observations to be described in this paper were made in connection with a study of auricular paroxysmal tachycardia. It is well known that quinidine frequently slows the cardiac rate in auricular paroxysmal tachycardia, and sometimes stops the paroxysm. The same effects may he produced by quinine, and the actions of these two drugs are, no doubt, similar. Singer and Winterberg ${ }^{1}$ have shown that in sinus tachyeardia quinine either does not alter the heart rate or inereases it somewhat. It seemed desirabie to investigate the effect of quinidine in sinus tachycardia.

A single dose of $0.6 \mathrm{Gm}$. of quinidine sulfate was given by mouth to each of five patients with sinus tarhycardia. Four of the patients had exophthalmic goiter, and the fifth had chronic ulcerative colitis with fever and anemia. In all five cases the heart. was organically sound, and none of the patients was receiving any drug which might affect the heart. The heart rate was counted at intervals before, and for at least two hours after, giving the quinidine, and electrocardiograms were likewise taken before giving the quinidine and two hours later.

The effect of quinidine upon the heart rate is shown in Table I. The rate was not affected or was slight.ly increased. These observations are similar to those of singer and Winterherg, ${ }^{1}$ who used quinine. They show that quinidine does not slow the rate of impulse formation in the sinoauricular node.

The electrocardiograms showed, in some instances, slight changes in the $\mathrm{T}$ waves after the administration of quinidine. With one exception, however, there were no significant alterations in the P-R or QRS intervals.

The one exception was Case 5, in which there was transient right bundle branch block two hours after the administration of the quinidine. Electrocardiograms taken a few minutes before the quinidine was given, and again on the following day, were essentially normal (Fig. 1). Multiple precordial leads showed relatively late activation of the right ventricle at the time when the bundle branch block was present. Two weeks later, $0.6 \mathrm{Gm}$. of quinidine sulfate was again given by mouth,

From the Department of Internal Medicine, Lniversity of Michigan Medical School, and the University Hospital.

This study was aided by a grant to Frank $N$. Wilson by the Horace H. Rackham School of Graduate Studies.

Received for publication Aug. 4, 1942. 
BARKER ET At.: SINIS TACHYCARDTA

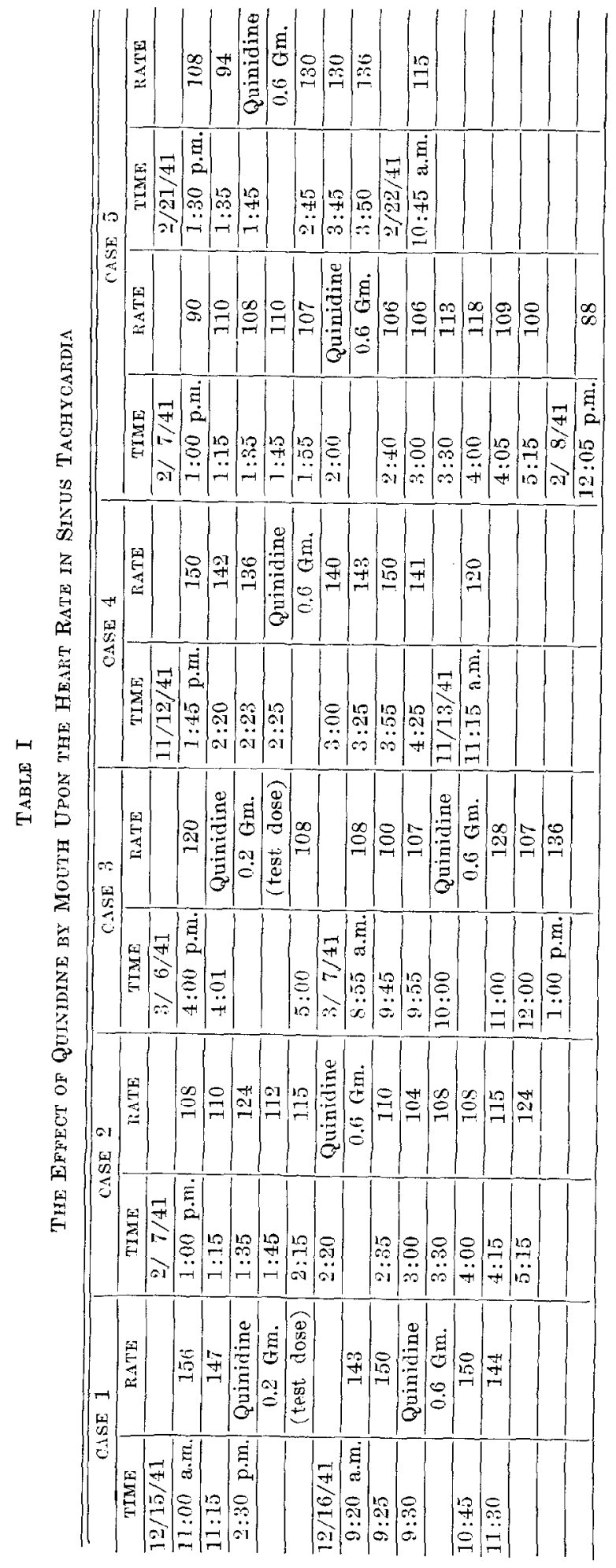


and two hours later the electrocadiogram again showed transient right hundle branch block (Fig. 2). Multiple precordial leads again showed relatively late activation of the right ventricle at the time when the bundle branch block was present. This observation is of interest in connection with the interpretation of the aberrant ventrieular deflections which are sometimes observed after the administration of quinicline to patients with auricular fibrillation.
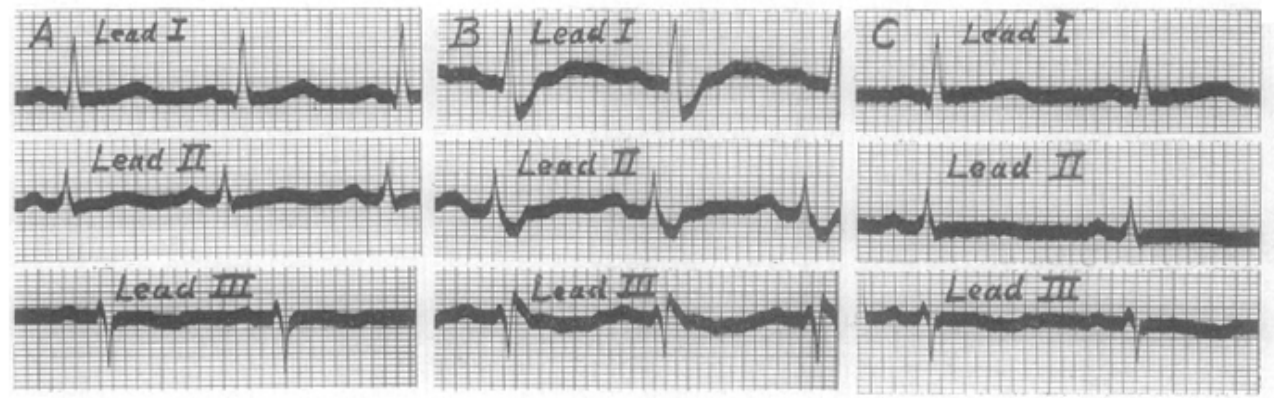

Fig. 1.-Quinidine sulfate, $0.6 \mathrm{Gm}$, by mouth at $2: 00$ P.M. A, Control curre. 1:55 P.M.

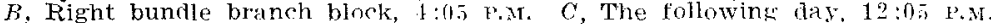
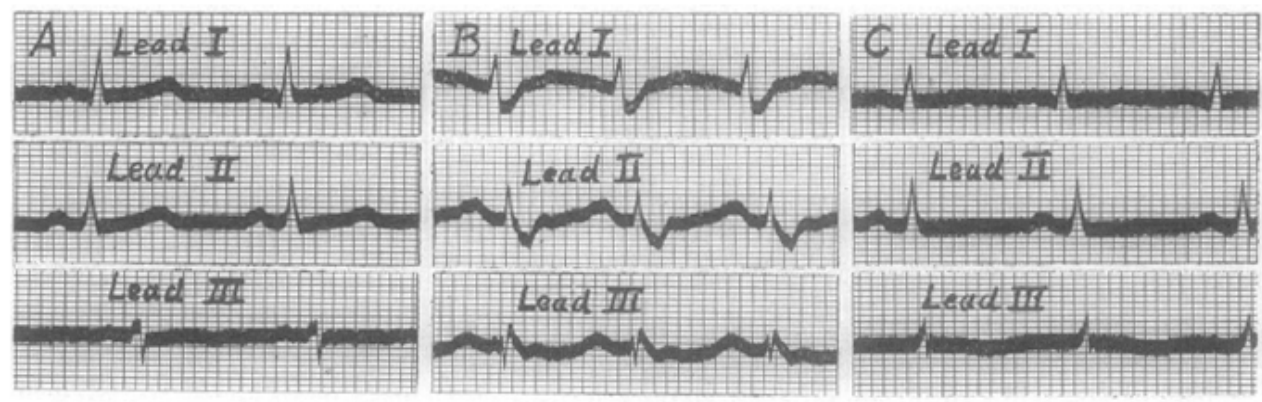

Fig. 3.-Two weeks after Fig. 1. Quinidine sulfate. 0.6 Gm., by mouth at $1: 45$ P.M. $A$, Control curve, $1: 35$ F, M. $B$, Right bundle braneh block, $3: 5 i$ P.M. $C$, The following day, 10:15 A.M.

When quinidine is administered in the reatment of auriculat fibrillation, and its effects followed closely by means of frepuent electrocardiograms, approximately one-third of the patients show abnormal QRS deffections.", a These resemble the abnormal complexes of actopice rontricular beats or of defective intraventricular comrluction. They oreur at the height of the quinidine effect, and disappear shortly after the quinidine has been stopperl.

It has been abundantly demonstrated that quinidine depresses intraventricular conduction, as shown by prolongation of the QRS interval,,$^{-9}$ and the abnormal QRS complexes which tollow quinidine have been attributed by some observers to defective intraventricular conduction." $5,7.9$ Furthermore, it is well known that quinidine may abolish ectopie ventricular beats, and that it is especially effective in stopping 
ventricular paroxysmal tachycardia. ${ }^{1 v, 11,12}$ Nevertheless, the abnormal QRS deflections which follow quimidine have been attributed by some observers to ectopic ventricular beats. ${ }^{2,6,10,13}$

In auricular fibrillation, quinidine almost invariably causes an increase in ventricular rate. This makes it specially difficult to distinguish between abnormal deflections caused by ectopic premature ventricular beats, occurring singly or in runs, and those caused by defective intraventricular conduction, which would be especially likely to appear at higher rates or after the shorter diastoles. Iuewis and his associates" have pointed out that there should be a close relation between prematurity and abnormality of ventricular deflections, if the abnormality were the result of impaired conductivity. They recognized that, in a general way, such a relationship existed, but did not consider it sufficiently close to indicate impaired intraventricular conductivity. In published electrocardiograms showing abnormal ventricular deflections which are attributed to ectopic ventricular beats caused by quinidine, alternative interpretations are possible, namely, that the ectopic beats oceurred spontaneously or for some other reason, and were not eaused by quinidine, or that the deflections were aberrant because of impaired intraventricular conductivity ${ }^{6,14}$

White, Marvin, and Burwell ${ }^{5}$ mentioned a case in which quinidine produced marked intraventricular block without abolishing the auricular fibrillation. Korns ${ }^{7}$ published curves from a palient who slowed bundle branch block after 6 grams of quinidine, which disappeared shortly after withdrawal of the drug; aurienlar fibrillation was present and the ventricular rate was 90 per minute, both in the presence of the bundle branch block and in its absence. Wilson, Wishart, Clark, and Herrmann ${ }^{3}$ described a case of auricular fibrillation in which all of the ventricular deflections became abnormal after $1.6 \mathrm{Gm}$. of quinidine. Normal rhythm returned two hours later, and all of the ventricular deflections were still abnormal; the normal type returned, however, as soon as the quinidine effect passed off. The abnormal deflections were attributed to impaired intraventricular conductivity.

In the present case, the aberrant ventricular deflections were clearly the result of impaired intraventricular conductivity caused by quinidine. It is our opinion that when quinidine causes abnormal QRS deflections, it does so by depressing conduction within the ventricles.

\section{SUMMARY}

A single dose of $0.6 \mathrm{Gm}$. of quinidine sulfate was given by mouth to each of five patients with sinus tachycardia. The cardiac rate was either not affected or was slightly increased.

In one patient, transient right bundle branch block occurred two hours after the administration of quinidine, upon two separate occasions.

When quinidine causes abnormal QRS deflections, it does so by depressing conduction within the ventricles. 
REFHRTANGH

1. Singer, R., and Winterberg, If.: Chinin als Herz-und Gefässmittel, Wien. Aroh. f. inn. Med. 3: 329, 1922 .

๑. Iewis, T., Drury, A. N., Wedd, A. M., and Ilieseu, C. C.: Obscrvations Upon the Actions of Certain Drugs Upon Fibrillation of the Auricles, Heart 9: $207,1922$.

3. Wilson, F. N., Wishart, S. W., Clark, N. F., and Herrmann, G. R.: Nature of Abnormal Ventricular Complexes During Quinidine Treatment of Aurieular Fibrillation, Proc. Soc. Exper. Biol. \& Med. 23: 273, 1926.

4. Lewis, T., Drury, A. N., Iliescu, C. C., and Wedd, A. M.: Observations Relating to the Action of Quinidine Upon the Dog's Heart; With Special Reference to Its Action on Clinical Fibrillation of the Auricles, Heart 9: 55, 1921.

5. White, P. I)., Marvin, H. M., and Burwell, C. S.: The Action of Quinidine Sulphate in Heart Disease, to Abolish the Cireus Movement of Aurienlar Flutter and Fibrillation, Boston M, \& \&, .T. 185: 647, 1921.

fi. Levy, R. I..: Clinical Studies of Quinidine. II. Alterations in the Cardiat Mechanism After Administration of Quinidine to Patients With Auricular Fibrillation With Consideration of Certain Toxir Effects of the Drug, Arch. Int. Med. 30: 451, 1928.

7. Jorns, H. M.: An Experimental and ('linimal Study of Quinidine Sulphate, Arch. Int. Med. 31: 15, 1923.

8. Gold, H., and Modall, W.: The Action of Quinidine on the Heart in the Normal Unanesthetized Dog, .J. Pharmacol. \& Hxper. 'L'herap. 46: 357, 1933.

9. Gold, H., and Otto, H. I.. The Use of Quinidine in Ambulatory Patients for the Prevention of Paroxysms of Auricular Flutter and Fibrillation; With Fspecial Reference to Dosage and the Lffects Upon Intraventrieular Conduction, ART. HFakT .J. 9: 2219, 193:i.

10. Hepburn, I., and Rykert, H. E.: The Use of Quinidine Sulfate Intravenously

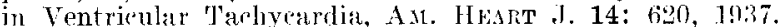

1. Cohn, A. F., anıl Tave, R. L.: Experimental Studies of the Pharmacology of Quinidine, Proc. Soc. Exper. Biol. \& Med. 18: 28:', 1!tyl.

12. Wilson, F. N., Wishart, S. W., Macleod, A. G., and Barker, P. S.: A Clinical Type of Paroxysmal Tachyearlia of Ventricular Origin in Which Paroxysms are Inducted hy Fxertion, AM. HEAfT .J. 8: 155, 19:3..

13. Mavmard, F. P.: Five Years' Experience in the Treatment of chronie Aurieular Fibrilation Witl Quinidine, Am. .J. M. Ne. 175: 5.5, 1928.

14. Jezer, A., and Srohwartz, S. P.: Unusual Manifestations Following the Use of' Quinidine Sulphate in a Patient. With Aurieular Flutter, Ax. Harat J. 10: 134, 1934 . 